\title{
Bullying victimization and child sexual abuse among left- behind and non-left-behind children in China
}

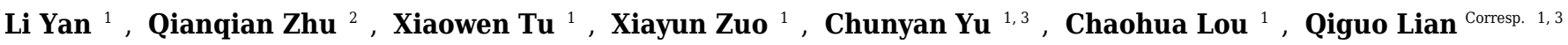 \\ ${ }^{1}$ Key Lab of Reproduction Regulation of NPFPC, SIPPR, IRD, Fudan University, Shanghai, China \\ 2 Shanghai Ninth People's Hospital, Shanghai Jiaotong University School of Medicine, Shanghai, China \\ 3 School of Public Health, Fudan University, Shanghai, China \\ Corresponding Author: Qiguo Lian \\ Email address: qglian@fudan.edu.cn
}

Background: Bullying is one of the most important factors associated with child abuse. However, robust tests supporting the assumption that being bullied can contribute to child sexual abuse (CSA) among leftbehind children (LBC) remain sparse. This study aims to investigate the association of bullying victimization with CSA among LBC in China.

Methods: A cross-sectional study was conducted in six middle schools of Sichuan and Anhui province in 2015. The bullying victimization was assessed by seven items from the Revised Olweus Bully/Victim Questionnaire. The experience of CSA was measured by ten items CSA scale with good consistency.

Results:A total of 1030 children met the sampling criteria, including 284 LBC and 746 non-LBC. The prevalence of CSA was $22.89 \%$ in $L B C$ and $20.19 \%$ in non- $L B C(p>0.05)$. Bullying victimization was related to CSA among both $\mathrm{LBC}$ (adjusted Odds Ratio $[\mathrm{aOR}]=2.52,95 \%$ confidential interval $[\mathrm{Cl}]=1.34$ 4.73) and non- $\mathrm{LBC}(\mathrm{aOR}=2.35,95 \% \mathrm{Cl}=1.58-3.53)$. The association between bullying victimization and CSA was much higher among left-behind girls (left-behind girls: $a O R=7.36,95 \% \mathrm{Cl}=2.16-24.99$; non-leftbehind girls: $\mathrm{aOR}=2.38,95 \% \mathrm{Cl}=1.08-5.27)$. Besides, $\mathrm{LBC}$ with young age (11-15), children with siblings, living in rural areas and non-traditional family structure who were bullied were more likely to suffer CSA than their non-LBC peers.

Conclusions:Bullying victimization is associated with a significant increase in CSA among both LBC and non-LBC. Anti-bullying programs should target vulnerable populations including female LBC and LBC with siblings to reduce the risk of CSA. 
1 Bullying victimization and child sexual abuse among left-behind and non-left-behind 2 children in China

3

4 Li Yan ${ }^{1} \mathrm{MD}$, Qianqian $\mathrm{Zhu}^{2} \mathrm{PhD}$, Xiaowen $\mathrm{Tu}^{1} \mathrm{PhD}$, Xiayun Zuo ${ }^{1} \mathrm{PhD}$, Chunyan $\mathrm{Yu}^{1,3} \mathrm{MD}$, 5 Chaohua Lou ${ }^{1} \mathrm{MD}$, Qiguo Lian ${ }^{1,3 *} \mathrm{MD}$

6

7 1. Key Lab of Reproduction Regulation of NPFPC, SIPPR, IRD, Fudan University, Shanghai, 8 China

9 2. Shanghai Ninth People's Hospital, Shanghai Jiaotong University School of Medicine, Shanghai, 10 China

11 3. School of Public Health, Fudan University, Shanghai, China

12

\section{Corresponding Author:}

Qiguo Lian

Key Lab of Reproduction Regulation of NPFPC, SIPPR, IRD, Fudan University

779 Laohumin Road, Shanghai 200237, China

Email: qglian@fudan.edu.cn

Telephone:8621-6477-1759 
20

21

22

\section{Abstract}

Background: Bullying is one of the most important factors associated with child abuse. However, robust tests supporting the assumption that being bullied can contribute to child sexual abuse (CSA) among left-behind children (LBC) remain sparse. This study aims to investigate the association of bullying victimization with CSA among LBC in China.

Methods: A cross-sectional study was conducted in six middle schools of Sichuan and Anhui province in 2015. The bullying victimization was assessed by seven items from the Revised Olweus Bully/Victim Questionnaire. The experience of CSA was measured by ten items CSA scale with good consistency.

Results: A total of 1030 children met the sampling criteria, including 284 LBC and 746 non-LBC. The prevalence of CSA was $22.89 \%$ in $\mathrm{LBC}$ and $20.19 \%$ in non-LBC $(p>0.05)$. Bullying victimization was related to CSA among both $\mathrm{LBC}$ (adjusted Odds Ratio $[\mathrm{aOR}]=2.52,95 \%$ confidential interval $[\mathrm{CI}]=1.34-4.73)$ and non-LBC $(\mathrm{aOR}=2.35,95 \% \mathrm{CI}=1.58-3.53)$. The association between bullying victimization and CSA was much higher among left-behind girls (left-behind girls: aOR=7.36, 95\%CI=2.16-24.99; non-left-behind girls: aOR=2.38, 95\%CI=1.085.27). Besides, LBC with young age (11-15), children with siblings, living in rural areas and nontraditional family structure who were bullied were more likely to suffer CSA than their non-LBC peers.

Conclusions: Bullying victimization is associated with a significant increase in CSA among both LBC and non-LBC. Anti-bullying programs should target vulnerable populations including female LBC and LBC with siblings to reduce the risk of CSA. 
41 Keywords: School bullying, Left-behind children, Child sexual abuse

42 
43

44 Child sexual abuse(CSA) can occur regardless of culture, ethnic heritage, gender or income level,

\section{Introduction} and the prevalence of CSA ranged from $8 \%$ to $31 \%$ for girls and $3 \%$ to $17 \%$ for boys around the whole world(Barth et al. 2013). In China, the prevalence of CSA experience before the age of 16 years ranged from $10.2 \%$ to $35.2 \%$, showing that CSA has become a huge concern in China(Yu et al. 2017). CSA includes a broad and often inconsistent range of behaviors in different studies. Some studies include only physical contact, whereas others also include non-contact sexual abuse. World Health Organization defines sexual abuse as "the involvement of a child in sexual activity that he or she does not fully comprehend, is unable to give informed consent to, or for which the child is not developmentally prepared, or else that violates the laws or social taboos of society"(WHO 2010). CSA has a negative impact on the psychological and educational functions of adolescents and youth(Meinck et al. 2015a). The variety of adverse outcomes include risks for bullying victimization(Hebert et al. 2016), unintended pregnancy and sexual abuse perpetration(Meinck et al. 2015a). Exiting research has identified some individual risk factors that increase risks for CSA, including gender, age, family constellation, parental characteristics, roles of school bullying, and so on(Meinck et al. 2015b).

School bullying, including physical, verbal, property and relational bullying, is pervasive around the world(Coyne et al. 2006). In China, $66.1 \%$ of boys and $48.8 \%$ of girls suffered one or more kinds of school bullying; $8.1 \%$ of boys and $2.9 \%$ of girls experienced more than four types of school bullying in 2009(Yi-juan et al. 2009). The newly reported incidences of bullying victimization, perpetration and witnessing were $26.10 \%, 9.03 \%$, and $28.90 \%$ respectively, 
64 according to the updated national representative survey data collected in 2016(Han et al. 65 2017).Most importantly, the consequences of school bullying can be severe and persistent, 66 including mental health problems, self-harm, and suicide (Lereya et al. 2015). Some youth being 67 bullied in school may also be the victims in other settings, such as their family and

communities(Holt et al. 2007). A study showed that physical assault in the community doubled the risk of sexual abuse for girls(Meinck et al. 2015a). Another study found that school bullying was associated with increased risk of CSA, the prevalence of CSA was $12.1 \%$ in victims and decreased to $3.1 \%$ in non-involved students(Holt et al. 2007).

The left-behind children(LBC), a particular group with a higher risk of getting mental health problems in rural China, are defined as the children who stay in rural areas more than six months with one or both their parents heading to urban areas for work(Wang et al. 2015). The number of LBC in China has reached 61.02 million in 2010, accounting for $21.88 \%$ of all children in China (Liu et al. 2016). Although millions of migrant parents pursue better opportunities for their children, their children left behind actually live in a situation lacking parental care and nurturance and are more likely to suffer abuse than others(Zhao et al. 2015). LBC were more likely to report being bullied (Otake et al. 2017), and suicide attempts (Chang et al. 2017) than non-LBC did in China.

Children being bullied by their peers are more likely to suffer sexual abuse can be explained somewhat by the developmental victimology framework(Finkelhor \& Dziuba-Leatherman 1994). Developmental victimology is the study of the broad spectrum of children's victimizations during all childhood, and the effort to understand the overlaps, common risk factors, interrelationships, 
85

86

87

and sequencings. The explanations show that children who involved in any kinds of victimizations such as family instability, lack of supervision, and bullying might create a risk for additional types of victimization(Finkelhor \& Dziuba-Leatherman 1994).

Although available studies examined risk factors associated with school bullying and sexual abuse separately(Hinduja \& Patchin 2012; Madu \& Peltzer 2001), there is scientific evidence indicating that bullying victimization was a potential risk factor for CSA (Hebert et al. 2016). The survey including 8194 students aged 14-18 years attending public and private schools in Quebec showed that school bullying was significantly associated with $\operatorname{CSA}(\beta=0.36 ; p<0.001)$ as well as cyberbullying $(\beta=0.40 ; p<0.001)$. However, the link between CSA and bullying victimization remains unexplored mainly among LBC in China. Hence, there is an urgent need to understand the importance of bullying victimization as the predictor for CAS among LBC and non-LBC in China. Also, it is essential to identify changeable factors that may amplify the risk. We hypothesized that (1) bullying victimization was positively associated with experience of CSA, and (2) the association in LBC was stronger than that in non-LBC.

\section{Method}

\section{Study site and participants}

The study was a cross-sectional study conducted in Anhui and Sichuan provinces from January 2015 to May 2015. Those two provinces are the top 2 most prominent origins of migrants in China (Liu et al. 2015; Yang et al. 2016). The target population comprised LBC and non-LBC aged 1118 years in middle schools and high schools. In this study, we defined LBC as children who were 
105

106

107

108

109

110

111

112

113

114

115

116

117

118

119

120

121

122

123

124

125

left behind by either one or both parents and stayed at home with extended family members more

than six months (Fan et al. 2010; Wang et al. 2015).

We selected one junior high school and one senior high school in Sichuan province and two junior high schools and two senior high schools in Anhui Province using purposive sampling to oversample the LBC. We adopted random cluster sampling to select 2-3 classes in grades7-12 in each school. All students in each selected class were included in the survey. We recruited 1063 children and dropped 33 children aged over 18, resulting in a sample size of 1030.

The study was reviewed and approved by the institutional review board of Shanghai Institute of Planned Parenthood Research (PJ2015-05). All participants provided oral consent before the survey. Passive consents were obtained from school administrators and children's parents/guardians.

\section{Measures}

In this study, a questionnaire survey was conducted using computer-assisted self-interviewing (CASI) technology in school computer labs. The content of the questionnaire included the background information (individual characteristics, family, and school information), the experiences of bullying victimization and CSA.

\section{Bullying victimization}

According to the Revised Olweus Bully/Victim Questionnaire by Dan Olweus which has been used in China(Tang et al. 2018), we selected seven items to identify the victims of bullying. The internal consistency of the scale was acceptable (Cronbach's alpha $=0.79$ ). The seven items comprising the scale are listed as follows: 
126 a. I was called mean names, was made fun of, or teased in a hurtful way.

127 b. Other students left me out of things on purpose, excluded me from their group of friends, or 128 completely ignored me.

129 c. I was hit, kicked, pushed, shoved around, or locked indoors.

$130 \mathrm{~d}$. Other students told lies or spread false rumors about me and tried to make others dislike me.

e. Other students made sexual jokes, comments, or gestures to me.

f. I was bullied by my classmates using a computer or e-mail message or pictures.

g. I was threatened or hurt by my classmates with swords, clubs and other weapons.

134 The responses were coded as " 0 =never, $1=1-2$ times/year, $2=3-5$ times/year, $3=6-11$ times/year, 4 =1-2times/month, 5 =1-2times/week, $6 \geq 2$ times/week".

136 The total score ranged from 0 to 42, with higher scores indicating severer experiences of being 137 bullied. We divided the children into two groups (low and high score victims) according to the 138 median score due to non-normal distribution.

\section{CSA}

We used CSA scale with ten items to measure the CSA experience (Chen et al. 2002), and the internal consistency was also acceptable (Cronbach's alpha=0.69). The CSA scale includes two forms of CSA (non-physical contact and physical contact) and the ten items are listed below(Halperin et al. 1996):

144 a. Has an adult or an older child ever not respected you by demanding you or forcing you to look 145 at pornographic pictures, drawings, films, videotapes or magazines?

b. Has an adult or an older child ever not respected you by sexually explicit talk or hostile 
147 language?

148 c. Has an adult or an older child ever not respected you by demanding you or forcing you to be 149 naked and to expose your genitals for picture taking or filming?

150 d. Has an adult or an older child ever not respected you by demanding you or forcing you to look 151 at his/her genitals or watch him/her masturbate?

152 e. Has an adult or an older child ever peeked at your breast or genital?

153 f. Has an adult or an older child ever not respected you by demanding you or forcing you to be 154 fondled (caresses, rubs, kisses on the whole body and/or your genitals)?

155 g. Has an adult or an older child ever not respected you by demanding you or forcing you to be 156 fondled him/her (caresses, rubs, kisses on the whole body and/or his/her genitals)?

157 h. Has an adult or an older child ever not respected you by demanding you or forcing you to submit 158 to having his/her fingers or an object introduced into your body?

159 i. Has an adult or an older child ever tried to making anal sex or vaginal sex with you?

$160 \mathrm{j}$. Has an adult or an older child ever made anal sex or vaginal sex with you?

161 The options of the ten items were all binary $(1=y e s, 0=$ no). The children suffered CSA if they 162 answered yes to any of these items(Hawton et al. 2018; Peterson et al. 2018; Sanchez et al. 2017).

\section{Covariates}

164 We controlled eight variables (age, gender, only-child, current place of residence, family structure, relationship with mother and father, parental educational level) as potential confounders because they were associated with the CSA and school bullying (Wolke et al. 2013). 
168

169

170

171

172

173

174

175

176

177

178

179

180

181

182

183

184

185

186

187

as urban area and rural area. We defined family structure as traditional if students' biologic parents married to each other at the time of the survey. We assessed parent-child relationship using the questions "how is your relationship with your mother and father respectively" with options "1=good, $2=$ general, and 3=poor". We measured parental educational level by the higher level of educational attainment of both parents, ranging from $1=$ below junior high school to $3=$ college degree or above.

\section{Statistical analysis}

The Stata/SE 15.1 (StataCorp, LLC) was used to analyze the data. Descriptive analyses were performed using frequencies and percentages. Chi-square tests were performed to evaluate differences in categorical variables including socio-demographic characteristics among LBC and non-LBC. The median was used to divide the bullying scores into two groups due to skewed distribution.

We investigated the association between bullying victimization and CSA using logistic regression models, with and without controlling for potential confounders, including age, only-child, current place of residence, family structure, relationship with mother and father and parental educational level among LBC and non-LBC. Besides, subgroup analysis stratified by gender, age, only child, current place of residence and family structure were also performed. The statistical significance was considered at $p<0.05$ for two-sided tests.

\section{Results}

\section{General information}


188 The final sample consisted of 1030 children, including 284 LBC (27.57\%) and 746 non-LBC

189 (72.43\%). Among the 284 LBC, the prevalence of being left behind by their father only, mother

190 only or both parents was $43.31 \%, 13.73 \%$ and $42.96 \%$ respectively.

191 The demographic characteristics of the LBC and non-LBC groups were shown in Table1. We

192 didn't observe any significant differences in age, gender, only child and parental educational

193 level between the two groups.

194 A total of $76.76 \%$ of LBC lived in rural areas, and the rate was $65.95 \%$ in non-LBC. The rate of

195 living with a divorced or single parent was $18.66 \%$ in $\mathrm{LBC}$ and $11.26 \%$ in non-LBC. The two

196 differences were both statistically significant $(p<0.05)$.

197 The rate of poor relationship with mother was $4.24 \%$ and $2.43 \%$ in $\mathrm{LBC}$ and non-LBC, the rate of

198 poor relationship with father was $6.03 \%$ and $3.52 \%$ in LBC and non-LBC. These differences were

199 also both significant $(p<0.05)$, indicating that LBC tended to have a poor relationship with parents

200 than their peers. The rate of bullying victimization was similar in LBC and non-LBC, and so did

201 CSA (Table 1).

202 Association between bullying victimization and CSA

203 The results of the crude odds ratio (cOR), adjusted odds ratio (aOR) and their 95\% confidence

204 intervals (CIs) were reported in Table 2-3. Bullying victimization was significantly related to CSA

$205(\mathrm{cOR}=2.04$ and $\mathrm{aOR}=2.52$ for $\mathrm{LBC}, \mathrm{cOR}=2.25$ and $\mathrm{aOR}=2.35$ for non-LBC $)$, suggesting that

206 victims of bullying were more likely to suffer sexual abuse among both LBC and non-LBC.

207 The results also indicated that victimization was significantly associated with higher proportion of

208 CSA among female $\mathrm{LBC}(\mathrm{cOR}=6.01$ and $\mathrm{aOR}=7.36)$ than that of female non-LBC $(\mathrm{cOR}=2.30$ and 
$209 \mathrm{aOR}=2.38$ ). Participants who were bullied were at higher risk of being sexually abused in younger

210 age $(\mathrm{cOR}=2.56$ and $\mathrm{aOR}=3.42$ for $\mathrm{LBC}, \mathrm{cOR}=2.86$ and $\mathrm{aOR}=3.32$ for non-LBC $)$ than those aged

211 16-18 years. Non-traditional family structure puts the bullying victims at higher chance of being

212 sexually abused ( $\mathrm{cOR}=4.23$ and $\mathrm{aOR}=12.25$ for non-LBC).

213 We also observed that victims of bullying who had siblings (cOR=2.89 and $\mathrm{aOR}=3.85$ for $\mathrm{LBC}$,

$214 \mathrm{cOR}=2.31$ and $\mathrm{aOR}=2.58$ for non-LBC), or lived in rural areas $(\mathrm{cOR}=2.66$ and $\mathrm{aOR}=2.97$ for $\mathrm{LBC}$,

$215 \mathrm{cOR}=2.60$ and $\mathrm{aOR}=2.92$ for non-LBC) were more likely to suffer CSA.

\section{Discussion}

217 We investigated the association between bullying victimization and CSA among LBC and non-

218 LBC from Anhui and Sichuan provinces, which was unexplored in Chinese culture before. Our

219 results indicated that CSA was a major concern and affected a significant proportion of LBC,

220 especially in those who were more vulnerable, namely victims of bullying.

221 The prevalence of CSA in the present study was $22.89 \%$ in LBC and $19.17 \%$ in non-LBC, which

222 echoes the findings of other studies abroad ranging from $7.00 \%$ to $29.87 \%$ (Afifi et al. 2003; S.A

223 et al. 2001). The prevalence was the highest(29.87\%) in high school students (S.A et al. 2001) and

224 lowest(7.00\%) in primary school students (Afifi et al. 2003). Our results were within the range

225 because our participants included both junior and senior high students.

226 Few existing studies have reported the dose-response relationship between bullying victimization

227 and CSA. One review article suggested that exposure to bullying was an identified correlate of

228 sexual abuse, however, the authors didn't mention the contribution of bullying victimization to the 
229

230

231

232

233

234

235

236

237

238

239

240

241

242

243

244

245

246

247

248

249

development of sexual abuse (Meinck et al. 2015b).The literature on poly-victimization claimed that victims of abuse were prone to suffer other types of abuses (Finkelhor et al. 2007), which was confirmed in our study where we observed a potential dose-response relationship between bullying victimization and CSA, the high score victims were accompanied by higher risk of being sexually abused in both $\mathrm{LBC}(\mathrm{aOR}=2.52,95 \% \mathrm{CI}=1.34-4.73)$ and non-LBC $(\mathrm{aOR}=2.35,95 \% \mathrm{CI}=1.58$ $3.53)$.

Based on existing research(Wolke et al. 2013), we identified and controlled a range of potential confounders(Andersson \& Ho-Foster 2008; Austin et al. 2018; Carey et al. 2008; Ibrahim et al. 2008; Shams et al. 2017; White \& Warner 2015). After adjusting for potential confounders, the contribution of bullying victimization to the sexual abuse increased from 6.01 times $(95 \% \mathrm{CI}=1.90$ $19.09)$ to 7.36 times $(95 \% \mathrm{CI}=2.16-24.99)$ among left-behind girls.

We noticed that the association between bullying victimization and CAS was significant only among the female $\mathrm{LBC}(\mathrm{aOR}=7.36,95 \% \mathrm{CI}=2.16-24.99)$, suggesting that female victims are more likely to be sexually abused(Meinck et al. 2015a). Besides, CSA was associated with bullying victimization among $\mathrm{LBC}$ aged $11-15$ years $(\mathrm{aOR}=3.42,95 \% \mathrm{CI}=1.18-9.93)$. However, the association wasn't significant within the older group, which indicated early adolescence was a critical transitional period (11-15 years old) for sexual abuse, which was worthy of public attention (Hamil-Luker et al. 2004). Thus, CSA caused by bullying victimization is preventable, if the school or main caregivers could put more attention on this age group.

The risk of victims of bullying suffered sexual abuse was 3.85 times in LBC who had siblings, while the risk was not observed in LBC who had no siblings. The possible explanation behind was 
250 LBC who had siblings got less care from parents than their only-child peers did, and parental care 251 could prevent victims of bullying from being sexually abused (Dai et al. 2017). Victims of bullying

252 living with or without traditional family structure were more likely to suffer sexual abuse (for 253 traditional family: $\mathrm{aOR}=2.20,95 \% \mathrm{CI}=1.54-3.14$; for non-traditional family: $\mathrm{aOR}=5.95,95 \% \mathrm{CI}=$ 254 1.46-24.21). Parents divorced or died may have a worse contribution to CSA in non-LBC, while 255 living apart could threaten the relationship and secure attachment with parents in LBC(Wang et al. 2015). Parental departure actually could reduce parents' support and supervision and increase the risk of suffering abuse and neglect(Zhao et al. 2015). One study indicated that the care of mother was the key protective factor for the mental resilience of $\mathrm{LBC}$, and the probable cause was that most children felt the strongest attachment to their mothers, given that in most cases mother was the primary caregiver and was difficult to be replaced(Qiaolan et al. 2011). What's more, other studies have shown that parental psychiatric problems, domestic violence, and disinterested mother could contribute to CSA (Afifi et al. 2003; S.A et al. 2001).

Bullying victimization was associated with CSA in both $\mathrm{LBC}(\mathrm{aOR}=2.97,95 \% \mathrm{CI}=1.42-6.22)$ and non-LBC $(\mathrm{aOR}=2.92,95 \% \mathrm{CI}=1.74-4.89)$ who lived in rural areas. Rural and urban areas differed from some important variables including socioeconomic status, liberalism/conservatism, and poverty rates(Kowalski et al. 2017). Compared with their urban counterparts, rural children might get less care from their parents when they were bullied in school because of the poor living environment, which increased the risk of being sexually abused(Xia et al. 2010).

Limitations 
271 to infer causality. The relationship between bullying victimization and CSA may be bidirectional

272 (Duncan 1999; Meinck et al. 2015a), and further studies with longitudinal design are needed.

273 Second, the self-reported experience of bullying victimization and CSA may result in recall bias.

274 Thus, the prevalence of bullying victimization and CSA could be underestimated. However, the

275 CASI technology we adopted in the survey can protect the privacy of children better and

276 substantially reduce the information bias(Brown et al. 2008). Third, our findings from school

277 students may not be generalized to adolescents that have dropped out of school. Fourth, we

278 simplify condensed the experience of CSA with ten items in one dummy variable (yes/no), which

279 may lead to biased results of the current study. The effect of bullying victimization on severity of

280 CSA need to be explored in future studies.

281 Despite these limitations, our findings demonstrate that bullying victimization increases the risk 282 of CSA and add evidence that individual characteristics, including younger, female, only-child, 283 rural area, and non-traditional family, may amplify the adverse effects of being bullied on CSA 284 among Chinese LBC. Our study suggests that anti-bullying interventions targeted at those 285 vulnerable populations may enhance the protective effects on CSA among over 61.02 million 286 Chinese LBC.

\section{Conclusion}

288 Our findings attest that victims of bullying among both LBC and non-LBC are more likely to suffer 289 CSA, which has significant implications for bullying intervention. Screening for peer bullying in 290 schools may help reduce the risk of CSA, given that CSA, in most cases, is insidious and subtle. 
291 Our results highlight the female victims of bullying are more vulnerable to CSA. Besides, the

292 children who live in rural areas or who have siblings are also susceptible to CSA after being 293 bullied. Thus, more attention should be paid to these vulnerable children to lower the risk of CSA.

294 Since the present study is the first step in understanding the relationship between bullying 295 victimization and CSA among Chinese LBC, future studies should also point to the contribution 296 of social support to resilience enhancement in victims of school bullying.

\section{Acknowledgments}

298 The authors thank site coordinators for their hard work. The authors also appreciate the cooperation 299 of the children involved. This study was funded by scientific research program of Shanghai 300 Municipal Health and Family Planning Commission (No. 201540091), Innovation-oriented 301 Science and Technology Grant from NPFPC Key Laboratory of Reproduction Regulation 302 (No.CX2017-5) and United Nations Population Fund (Grant No.PL-SSA20). The funders had no 303 involvement in any aspect of the research, including in the study design, data collection, data 304 analysis, data interpretation, writing of the report, or the decision to submit the paper for 305 publication. 
306

307

308

309

310

311

312

313

314

315

316

317

318

319

320

321

322

323

324

325

326

327

328

329

330

331

332

333

334

335

336

337

338

339

340

341

342

343

344

345

346

\section{References}

Afifi Z, El Lawindi M, Ahmed SA, and W Basily W. 2003. Adolescent abuse in a community sample in Beni Suef, Egypt: Prevalence and risk factors. Eastern Mediterranean health journal 9:1003-1018.

Andersson N, and Ho-Foster A. 2008. 13,915 reasons for equity in sexual offences legislation: A national schoolbased survey in South Africa. International Journal for Equity in Health 7:1-6. 10.1186/1475-9276-7-20

Austin AE, Shanahan ME, and Zvara BJ. 2018. Association of childhood abuse and prescription opioid use in early adulthood. Addictive Behaviors 76:265-269. https://doi.org/10.1016/j.addbeh.2017.08.033

Barth J, Bermetz L, Heim E, Trelle S, and Tonia T. 2013. The current prevalence of child sexual abuse worldwide: a systematic review and meta-analysis. International Journal of Public Health 58:469-483.

Brown JL, Vanable PA, and Eriksen MD. 2008. Computer-assisted self-interviews: A cost effectiveness analysis. Behavior research methods 40:1-7.

Carey PD, Walker JL, Rossouw W, Seedat S, and Stein DJ. 2008. Risk indicators and psychopathology in traumatised children and adolescents with a history of sexual abuse. European Child \& Adolescent Psychiatry 17:93-98. 10.1007/s00787-007-0641-0

Chang H, Yan Q, Tang L, Huang J, Ma Y, Ye X, and Yu Y. 2017. A comparative analysis of suicide attempts in left-behind children and non-left-behind children in rural China. PLOS ONE 12:e0178743. 10.1371/journal.pone.0178743

Chen J, P.Dunne M, and Wang X. 2002. Prevalence of Childhood Sexual Abuse among Female Students in a Senior high School Chin J School Health 23:108-110. 10.3969/j.issn.1000-9817.2002.02.020

Coyne SM, Archer J, and Eslea M. 2006. "We're not friends anymore! unless...": the frequency and harmfulness of indirect, relational, and social aggression. Aggressive Behavior 32:294-307. 10.1002/ab.20126

Dai Q, Yang G, Hu C, Wang L, Liu K, Guang Y, Zhang R, Xu S, Liu B, and Yang Y. 2017. The alienation of affection toward parents and influential factors in Chinese left-behind children. European Psychiatry 39:114-122.

Duncan RD. 1999. Maltreatment by Parents and Peers: The Relationship between Child Abuse, Bully Victimization, and Psychological Distress. Child Maltreatment 4:45-55.

Fan F, Su L, Gill MK, and Birmaher B. 2010. Emotional and behavioral problems of Chinese left-behind children: a preliminary study. Social Psychiatry and Psychiatric Epidemiology 45:655-664. 10.1007/s00127-009-0107-4

Finkelhor D, and Dziuba-Leatherman J. 1994. Children as victims of violence: a national survey. Pediatrics 94:413420.

Finkelhor D, Ormrod RK, and Turner HA. 2007. Poly-victimization: A neglected component in child victimization. Child Abuse \& Neglect 31:7-26. https://doi.org/10.1016/j.chiabu.2006.06.008

Halperin DS, Bouvier P, Jaffe PD, Mounoud RL, Pawlak CH, Laederach J, Wicky HR, and Astie F. 1996. Prevalence of child sexual abuse among adolescents in Geneva: results of a cross sectional survey. BMJ 312:1326-1329.

Hamil-Luker J, Land KC, and Blau J. 2004. Diverse trajectories of cocaine use through early adulthood among rebellious and socially conforming youth. Social science research 33:300-321. 10.1016/s0049089x(03)00060-7

Han Z, Zhang G, and Zhang H. 2017. School Bullying in Urban China: Prevalence and Correlation with School Climate. Int J Environ Res Public Health 14. 10.3390/ijerph14101116

Hawton K, Norris T, Crawley E, and Shield JPH. 2018. Is Child Abuse Associated with Adolescent Obesity? A Population Cohort Study. Child Obes 14:106-113. 10.1089/chi.2017.0141

Hebert M, Cenat JM, Blais M, Lavoie F, and Guerrier M. 2016. Child Sexual Abuse, Bullying, Cyberbullying, and Mental 
Health Problems among High Schools Students: A Moderated Mediated Model. Depress Anxiety 33:623629. 10.1002/da.22504

Hinduja S, and Patchin JW. 2012. Bullying Beyond the Schoolyard: Preventing and Responding to Cyberbullying. Security Journal 25:88-89.

Holt MK, Finkelhor D, and Kantor GK. 2007. Hidden Forms of Victimization in Elementary Students Involved in Bullying. School Psychology Review 36:345-360.

Ibrahim NK, Jalali EA, Al-Ahmadi JR, and Al-Bar AA. 2008. Prevalence, risk factors and outcome of childhood abuse reported by female university students in jeddah. J Egypt Public Health Assoc 83:329-351.

Kowalski R, Giumetti GW, and Limber SP. 2017. Bullying and Cyberbullying Among Rural Youth. In: Michael KD, and Jameson JP, eds. Handbook of Rural School Mental Health. Cham: Springer International Publishing, 231245.

Lereya ST, Copeland WE, Costello EJ, and Wolke D. 2015. Adult mental health consequences of peer bullying and maltreatment in childhood: two cohorts in two countries. Lancet Psychiatry 2:524-531. 10.1016/S22150366(15)00165-0

Liu J, Liu S, Yan J, Lee E, and Mayes L. 2016. The impact of life skills training on behavior problems in left-behind children in rural China: A pilot study. School Psychology International 37:73-84. 10.1177/0143034315618442

Liu Y, Li X, Chen L, and Qu Z. 2015. Perceived positive teacher-student relationship as a protective factor for Chinese left-behind children's emotional and behavioural adjustment. Int J Psychol 50:354-362. 10.1002/ijop.12112

Madu SN, and Peltzer K. 2001. prevalence and patterns of child sexual abuse and victim-perpetrator relationship among a sample of university students. Archives of Sexual Behavior 30:311-321. 10.1023/a:1002704331364

Meinck F, Cluver LD, and Boyes ME. 2015a. Longitudinal Predictors of Child Sexual Abuse in a Large CommunityBased Sample of South African Youth. J Interpers Violence 32:2804-2836. 10.1177/0886260515596331

Meinck F, Cluver LD, Boyes ME, and Mhlongo EL. 2015b. Risk and Protective Factors for Physical and Sexual Abuse of Children and Adolescents in Africa:A Review and Implications for Practice. Trauma, Violence, \& Abuse 16:81-107. 10.1177/1524838014523336

Otake Y, Liu X, and Luo X. 2017. Involvement in Bullying Among Left-Behind Children in Provincial Chinese Cities: The Role of Perceived Emotional Support. Journal of Aggression, Maltreatment \& Trauma:1-15. 10.1080/10926771.2017.1410749

Peterson ZD, Janssen E, Goodrich D, Fortenberry JD, Hensel DJ, and Heiman JR. 2018. Child Sexual Abuse and Negative Affect as Shared Risk Factors for Sexual Aggression and Sexual HIV Risk Behavior in Heterosexual Men. Archives of Sexual Behavior 47:465-480. 10.1007/s10508-017-1079-1

Qiaolan L, Huan Z, Yang Y, Bingshuang H, Xiao M, and Huihui C. 2011. Structural equation model analysis on psychological resilience of left-behind children in rural areas in Sichuan Province. JOURNAL OF HYGIENE RESEARCH 40:445-449.

S.A J, S.N M, and Idemudia E. 2001. Perceived Parental Disorders as Risk Factors for Child Sexual, Physical and Emotional abuse among High School Students in the Mpumalanga Province, South Africa. 6:103-112. 10.1080/09718923.2002.11892337

Sanchez SE, Pineda O, Chaves DZ, Zhong QY, Gelaye B, Simon GE, Rondon MB, and Williams MA. 2017. Childhood physical and sexual abuse experiences associated with post-traumatic stress disorder among pregnant women. Ann Epidemiol 27:716-723 e711. 10.1016/j.annepidem.2017.09.012 
Shams H, Garmaroudi G, and Nedjat S. 2017. Factors Related to Bullying: A Qualitative Study of Early Adolescent Students. Iranian Red Crescent Medical Journal 19:1-9. 10.5812/ircmj.42834

Tang H, Yang L, Fu S, Zhang L, and Fu Y. 2018. Relationship between bullying and suicide-related behaviors among middle school students. Chin J Sch Health 39:60-63.

Wang L, Feng Z, Yang G, Yang Y, Dai Q, Hu C, Liu K, Guang Y, Zhang R, and Xia F. 2015. The epidemiological characteristics of depressive symptoms in the left-behind children and adolescents of Chongqing in China. Journal of Affective Disorders 177:36-41.

White CN, and Warner LA. 2015. Influence of family and school-level factors on age of sexual initiation. J Adolesc Health 56:231-237. 10.1016/j.jadohealth.2014.09.017

WHO. 2010. Violence and Health in the WHO African Region. p 16.

Wolke D, Copeland WE, Angold A, and Costello EJ. 2013. Impact of Bullying in Childhood on Adult Health, Wealth, Crime, and Social Outcomes. Psychological Science 24:1958-1970. 10.1177/0956797613481608

Xia Q, Xian-bin L, Jing Q, Yun L, and Kai-hong Z. 2010. Situation and influencing factors of maltreatment in childhood of 290 youngsters. CJCHC Jan 18:33-35.

Yang T, Li C, Zhou C, Jiang S, Chu J, Medina A, and Rozelle S. 2016. Parental migration and smoking behavior of leftbehind children: evidence from a survey in rural Anhui, China. Int J Equity Health 15:127. 10.1186/s12939016-0416-7

Yi-juan Q, Yi X, Cheng-ye J, and Lin Z. 2009. The prevalence of bullying behaviors among urban middle school students in 18 provinces,China. Chin J Epidemiol 30:444-447.

Yu B, Chen J, Jin Y, Zhang W, Feng Y, and Zhao X. 2017. The knowledge and skills related to sexual abuse prevention among Chinese children with hearing loss in Beijing. Disability and Health Journal 10:344-349. 10.1016/j.dhjo.2016.12.014

Zhao J, Liu X, and Wang M. 2015. Parent-child cohesion, friend companionship and left-behind children's emotional adaptation in rural China. Child Abuse \& Neglect 48:190-199. 
Table $\mathbf{1}$ (on next page)

Characteristics of the study population $(n=1030)$ 
Table 1 Characteristics of the study population $(n=1030)$

\begin{tabular}{|c|c|c|c|}
\hline Variables & $\begin{array}{l}\text { Total } \\
(\mathrm{n}=1030)\end{array}$ & $\begin{array}{l}\text { LBC } \\
(n=284)\end{array}$ & $\begin{array}{l}\text { Non-LBC } \\
(\mathrm{n}=746)\end{array}$ \\
\hline \multicolumn{4}{|l|}{ Age(years) } \\
\hline $11-15$ & $497(48.25)$ & $135(47.54)$ & $362(48.53)$ \\
\hline $16-18$ & $533(51.75))$ & $149(52.46)$ & $384(51.47)$ \\
\hline \multicolumn{4}{|l|}{ Gender } \\
\hline Boys & $485(47.09)$ & $127(44.72)$ & $358(47.99)$ \\
\hline Girls & $545(52.91)$ & $157(55.28)$ & $388(52.01)$ \\
\hline \multicolumn{4}{|l|}{ Grade } \\
\hline Junior high school & $489(47.48)$ & $134(47.18)$ & $355(47.59)$ \\
\hline High school & $541(52.52)$ & $150(52.82)$ & $391(52.41)$ \\
\hline \multicolumn{4}{|l|}{ Only child } \\
\hline Yes & $481(46.70)$ & $144(50.70)$ & $337(45.17)$ \\
\hline No & $549(53.30)$ & $140(49.30)$ & $409(54.83)$ \\
\hline \multicolumn{4}{|l|}{ Home place } \\
\hline Urban & $320(31.07)^{\#}$ & $66(23.24)$ & $254(34.05)$ \\
\hline Rural & $710(68.93)$ & $218(76.76)$ & $492(65.95)$ \\
\hline \multicolumn{4}{|l|}{ Family structure } \\
\hline Traditional & $893(86.70)^{*}$ & $231(81.34)$ & $662(88.74)$ \\
\hline Non-traditional & $137(13.30)$ & $53(18.66)$ & $84(11.26)$ \\
\hline \multicolumn{4}{|c|}{ Relationship with mother } \\
\hline Good & $899(88.05)^{\#}$ & $231(82.21)$ & $668(90.27)$ \\
\hline General & $92(9.01)$ & $38(13.52)$ & $54(7.30)$ \\
\hline Poor & $30(2.94)$ & $12(4.27)$ & $18(2.43)$ \\
\hline \multicolumn{4}{|c|}{ Relationship with father } \\
\hline Good & $832(81.49)^{*}$ & $217(76.95)$ & $615(83.22)$ \\
\hline General & $146(14.30)$ & $48(17.02)$ & $98(13.26)$ \\
\hline Poor & $43(4.21)$ & $17(6.03)$ & $26(3.52)$ \\
\hline \multicolumn{4}{|c|}{ Parental education level } \\
\hline Low & $796(78.35)$ & $226(80.43)$ & $570(77.55)$ \\
\hline General & $167(16.44)$ & $48(17.08)$ & $119(16.19)$ \\
\hline High & $53(5.22)$ & $7(2.49)$ & $46(6.26)$ \\
\hline \multicolumn{4}{|c|}{ Bullying victimization score } \\
\hline Low & $624(60.58)$ & $161(56.69)$ & $463(62.06)$ \\
\hline High & $406(39.42)$ & $123(43.31)$ & 283(37.94) \\
\hline \multicolumn{4}{|l|}{ CSA victims } \\
\hline No & $822(79.81)$ & $219(77.11)$ & $603(80.83)$ \\
\hline Yes & 208(20.19) & $65(22.89)$ & $143(19.17)$ \\
\hline
\end{tabular}

${ }^{*} p<0.05,{ }^{*} p<0.01$ 


\section{Table 2 (on next page)}

Adjusted associations between bullying victimization and CSA, stratified by gender, age, only child, home place, family structure 
1 Table 2 Crude associations between bullying victimization and CSA, stratified by gender, age, only child, home place, family 2 structure

\begin{tabular}{|c|c|c|c|}
\hline & $\begin{array}{l}\text { Total } \\
\text { OR( } 95 \% \mathrm{CI}, p \text { value })\end{array}$ & $\begin{array}{l}\text { LBC } \\
\text { OR(95\%CI, } p \text { value })\end{array}$ & $\begin{array}{l}\text { Non-LBC } \\
\text { OR(95\%CI, } p \text { value })\end{array}$ \\
\hline Bullying victimization & $2.20(1.62-3.00,<0.001)$ & $2.04(1.17-3.58,0.013)$ & $2.25(1.55-3.25,<0.001)$ \\
\hline \multicolumn{4}{|l|}{ Gender } \\
\hline Boys & $1.76(1.20-2.59,0.004)$ & $1.33(0.64-2.76,0.439)$ & $1.97(1.25-3.09,0.003)$ \\
\hline Girls & $3.23(1.77-5.90,<0.001)$ & $6.01(1.90-19.09,0.002)$ & $2.30(1.10-4.82,0.027)$ \\
\hline \multicolumn{4}{|l|}{ Age(years) } \\
\hline $11-15$ & $2.78(1.72-4.47,<0.001)$ & $2.56(1.03-6.38,0.044)$ & $2.86(1.63-5.00,<0.001)$ \\
\hline $16-18$ & $2.03(1.32-3.10,0.001)$ & $2.04(0.97-4.29,0.062)$ & $1.97(1.17-3.32,0.011)$ \\
\hline \multicolumn{4}{|l|}{ Only child } \\
\hline Yes & $1.94(1.25-3.01,0.003)$ & $1.57(0.73-3.38,0.252)$ & $2.16(1.26-3.69,0.005)$ \\
\hline No & $2.48(1.60-3.82,<0.001)$ & $2.89(1.24-6.75,0.014)$ & $2.31(1.39-3.85,0.001)$ \\
\hline \multicolumn{4}{|l|}{ Home place } \\
\hline Urban & $1.52(0.89-2.61,0.129)$ & $0.91(0.29-2.84,0.875)$ & $1.75(0.94-3.23,0.076)$ \\
\hline Rural & $2.64(1.81-3.85,<0.001)$ & $2.66(1.38-5.11,0.003)$ & $2.60(1.63-4.13,<0.001)$ \\
\hline \multicolumn{4}{|l|}{ Family structure } \\
\hline Traditional & $2.11(1.52-2.93,<0.001)$ & $2.05(1.11-3.75,0.020)$ & $2.12(1.44-3.13,<0.001)$ \\
\hline Non- traditional & $3.72(1.36-10.21,0.011)$ & $3.14(0.57-17.23,0.189)$ & $4.23(1.20-14.87,0.024)$ \\
\hline
\end{tabular}

3

4 


\section{Table 3(on next page)}

Crude associations between bullying victimization and CSA, stratified by gender, age, only child, home place, family structure 
1 Table 3 Adjusted associations between bullying victimization and CSA, stratified by gender, age, only child, home place, family 2 structure

\begin{tabular}{|c|c|c|c|}
\hline & $\begin{array}{l}\text { Total } \\
\text { OR ( } 95 \% \mathrm{CI}, p \text { value })\end{array}$ & $\begin{array}{l}\text { LBC } \\
\text { OR( } 95 \% \mathrm{CI}, p \text { value })\end{array}$ & $\begin{array}{l}\text { Non-LBC } \\
\text { OR( } 95 \% \mathrm{CI}, p \text { value })\end{array}$ \\
\hline Bullying victimization* & $2.35(1.68-3.30,<0.001)$ & $2.52(1.34-4.73,0.004)$ & $2.35(1.58,3.53,<0.001)$ \\
\hline \multicolumn{4}{|l|}{ Gender* } \\
\hline Boys & $2.02(1.34-3.03,0.001)$ & $1.32(0.58-2.98,0.501)$ & $2.34(1.44-3.79,0.001)$ \\
\hline Girls & $3.40(1.81-6.38,<0.001)$ & $7.36(2.16-24.99,0.001)$ & $2.38(1.08-5.27,0.032)$ \\
\hline \multicolumn{4}{|l|}{ Age (years)* } \\
\hline $11-15$ & $3.16(1.89-5.30,<0.001)$ & $3.42(1.18-9.93,0.023)$ & $3.32(1.80-6.15,<0.001)$ \\
\hline $16-18$ & $1.78(1.10-2.87,0.018)$ & $2.06(0.86-4.91,0.105)$ & $1.65(0.92-2.97,0.093)$ \\
\hline \multicolumn{4}{|l|}{ Only child* } \\
\hline Yes & $2.12(1.31-3.43,0.002)$ & $2.33(0.95-5.67,0.063)$ & $2.17(1.19-3.96,0.011)$ \\
\hline No & $2.81(1.72-4.57,<0.001)$ & $3.85(1.37-10.85,0.011)$ & $2.58(1.46-4.54,0.001)$ \\
\hline \multicolumn{4}{|l|}{ Home place* } \\
\hline Urban & $1.55(0.85-2.82,0.157)$ & $0.96(0.23-4.06,0.956)$ & $1.65(0.83-3.30,0.153)$ \\
\hline Rural & $2.82(1.86-4.26,<0.001)$ & $2.97(1.42-6.22,0.004)$ & $2.92(1.74-4.89,<0.001)$ \\
\hline \multicolumn{4}{|l|}{ Family structure* } \\
\hline Traditional & $2.20(1.54-3.14,<0.001)$ & $2.69(1.35-5.34,0.005)$ & $2.13(1.40-3.26,<0.001)$ \\
\hline Non-traditional & $5.95(1.46-24.21,0.013)$ & $11.72(0.36-379.20,0.165)$ & $12.25(1.51-99.63,0.019)$ \\
\hline
\end{tabular}

3 * Adjusted for potential confounders, including age, gender, only child, home place, family structure, relationship with mother, 4 relationship with father, parental educational level. 